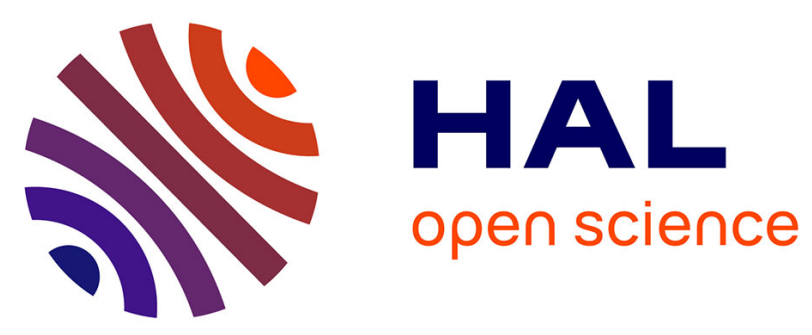

\title{
The Launch of Centre Mersenne, a Technical Infrastructure to Support the Move Towards Diamond Open Access
}

\author{
Thierry Bouche, Evelyne Miot, Célia Vaudaine
}

\section{- To cite this version:}

Thierry Bouche, Evelyne Miot, Célia Vaudaine. The Launch of Centre Mersenne, a Technical Infrastructure to Support the Move Towards Diamond Open Access. ELPUB 2018, Jun 2018, Toronto, Canada. 10.4000/proceedings.elpub.2018.10 . hal-01816812

\section{HAL Id: hal-01816812 \\ https://hal.science/hal-01816812}

Submitted on 15 Jun 2018

HAL is a multi-disciplinary open access archive for the deposit and dissemination of scientific research documents, whether they are published or not. The documents may come from teaching and research institutions in France or abroad, or from public or private research centers.
L'archive ouverte pluridisciplinaire HAL, est destinée au dépôt et à la diffusion de documents scientifiques de niveau recherche, publiés ou non, émanant des établissements d'enseignement et de recherche français ou étrangers, des laboratoires publics ou privés.

\section{(c)(1)}

Distributed under a Creative Commons Attribution| 4.0 International License 


\title{
The Launch of Centre Mersenne, a Technical Infrastructure to Support the Move Towards Diamond Open Access
}

\author{
Thierry Bouche, Evelyne Miot and Célia Vaudaine
}

\section{Introduction}

1 The Centre Mersenne for Open Scientific Publishing is a non-profit initiative that has been publicly launched in January 2018. Its goal is to build a comprehensive Open Access publishing infrastructure for scientific communities publishing in $\operatorname{LaTeX}^{1}[1]$. It is developed by Cellule Mathdoc, a joint service unit of the mathematical institute of CNRS ${ }^{2}$ and Université Grenoble Alpes (UGA) located in Grenoble (France), in partnership with UGA Éditions ${ }^{3}$.

2 The Centre Mersenne consists of a dissemination platform for scientific publications and a set of modular publishing services for editorial teams. Those services enable editorial committees or small organisations to professionally manage a publication, with all features relevant to their scientific communities without employing a commercial publisher.

3 Eligible scientific publications can be journals, proceedings, or books, in any scientific domain with a local or international base, provided they are engaged towards Diamond Open Access (aka no $\mathrm{APC}^{4}$ Gold OA: no subscription fee to read, no submission or publication fee to publish), and the documents are formatted in LaTeX, two principles that are the DNA of the project. 
The Centre Mersenne homepage

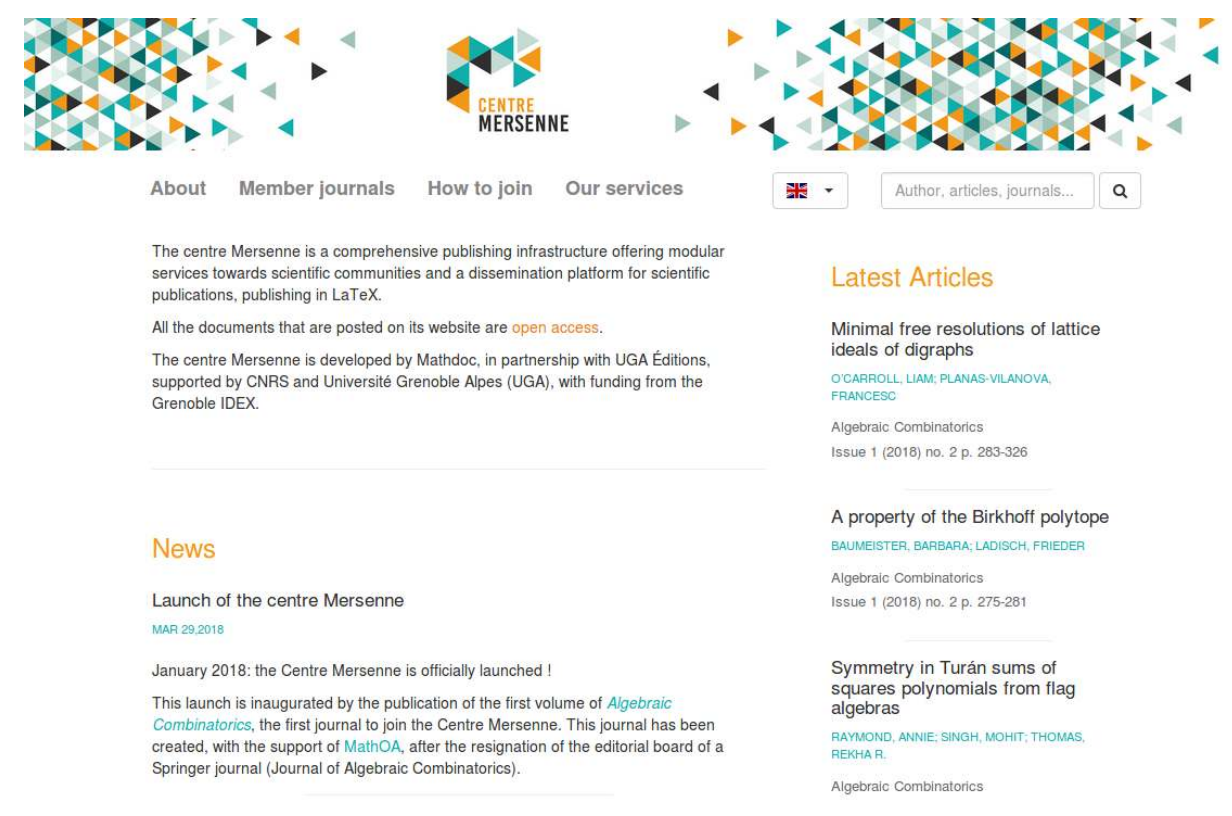

CNRS

\section{Context}

\section{Background: From Cedram Dissemination Platform to the Centre Mersenne for Open Scientific Publishing}

4 Several years ago, the French mathematical community joined forces to set-up a highquality online publishing platform for academically published research math journals [2]: the Cedram ${ }^{5}$ [3] was built by Cellule Mathdoc ${ }^{6}$, a public structure mainly staffed by CNRS, also supported by the university of Grenoble and developing various services towards French librarians and mathematicians, among which Numdam $[4]^{7}$ (the reference French digital mathematics library), an archive containing digitised journals, proceedings, theses and monographs (58,000 articles and 1,000,000 pages).

5 The Cedram comprised a dissemination platform and a few other services for mathematical journals publishing in LaTeX [5], it was launched in 2005. Cedram originally offered editorial teams services such as online posting, a LaTeX production workflow for serials, creation and maintenance of LaTeX styles, production of PDFs for print and web with XML/MathML metadata, $\mathrm{DOI}^{8}$ registration, reference linking... This publishing platform progressively evolved and extended its services range to $\mathrm{OJS}^{9}$ maintenance and LaTeX typesetting. To give some figures, in 2017, it contained 9 journals, one book, and 6 proceedings series and was producing and publishing 200 articles and 6,000 pages per year (8,500 articles, 200,000 pages currently online).

6 The Centre Mersenne is thus built on the expertise gained from the Cedram experience and intends to offer a more comprehensive structure, providing a stronger technical platform, opening up to international journals, to scientific disciplines outside mathematics (but with similar publishing practices), and offering more services. 


\section{Open Access As a Founding Principle}

7 The decision to make Diamond Open Access a founding principle of the Centre Mersenne is also an answer to a growing scientific community's call for alternative open access publishing solutions.

8 Researchers and academic libraries are indeed increasingly challenging the traditional system of scientific publishing, marked by the for-profit publishers oligopoly, where researchers have to pay to access and share their own publications and where libraries and institutions have to face ever rising costs of the "Big Deal" journal subscriptions. Those "Big Deals" are indeed being more and more questioned and cancelled.

9 In parallel, researchers (university or research staff, grant recipients) are progressively required by governments, institutions and funders in Europe [6], United States, Canada... to make their published, peer-reviewed journal articles and proceedings papers free to access (mandates). Meanwhile, more journals are converting to open access to meet these requirements [7].

10 The general idea is that publishing is part of the research activity and should be considered as a research infrastructure, thus controlled by the scientific community and essentially funded by research institutions. The Centre Mersenne is struggling to offer an effective and sustainable alternative open access publishing solution, in a similar fashion to initiatives such as OpenEdition ${ }^{10}$, Episciences ${ }^{11}$ (France), SciPost ${ }^{12}$ (Netherlands), ELibM ${ }^{13}$ (Germany).

\section{The project}

\section{A new dissemination platform}

11 Being more than a decade old, the Cedram system was starting to show its age. A new platform for hosting and disseminating digital content has been rewritten from scratch during the last two years. It has been first released for the Numdam Digital Library early 2017, and is now adapted to Centre Mersenne's publications. One important feature of the platform is that it uses internally a very standardised structure, but allows for a wide versatility in appearance, so as to endow each journal with a well recognised identity.

All of its content is open access, free for everyone to read and download.

\section{A range of services to facilitate journals management}

13 The Centre Mersenne offers services that provide the necessary technical and editorial tools to help editorial teams publish their journals or books:

14 Some are considered part of the infrastructure, thus are made available for free:

- Online publication and dissemination of articles on the Mersenne platform, including the creation of a specific web site for each publication but also DOI registration, reference linking (zbMATH ${ }^{14}, \mathrm{Crossref}^{15}$ ), interoperability through an OAI-PMH ${ }^{16}$ server (to allow anybody to search and reuse metadata) and long term preservation through the CLOCKSS solution $^{17}$, a non-profit "dark archive" that ensures long-term preservation of the content.

- Creation of a LaTeX style template within the Cedram class. 
- Installation of Open Journal System (OJS) for managing submissions and the refereeing process, including customisation of a dedicated instance adapted to the editorial board's evaluation process, maintenance and support but also documentation and training.

Other services, depending on each journal's publishing flow, will be charged, to make the infrastructure sustainable. Here are typical examples:

- Copy editing;

- LaTeX structure and layout editing;

- Managing editor, for journal workflow assistance;

- Plagiarism detection, through Crossref Similarity Check's tool;

- Printing (on demand or a posteriori).

\section{A team}

The team is headed by mathematicians, and comprises about ten people bringing diverse skills: IT specialists, a project manager, a LaTeX typesetter... The Centre Mersenne's team has been drawing on the expertise acquired through previous activities of Cellule Mathdoc (the Numdam digital library, the Cedram dissemination platform for mathematical publications).

\section{Governance}

17 The Centre Mersenne isn't a publisher but a platform and service provider. It relies on its governance bodies in order to decide on resource allocation.

Two governing bodies are responsible for selecting the publications joining it: the scientific committee, composed of reputable scientists, and the steering committee. Applications of journals wishing to join the Centre Mersenne are considered by the scientific committee on a regular basis. It gives an opinion on the scientific and operational quality of the project, it also helps prioritise the journals' applications and advise on development plans. The final decision is taken by the steering committee taking into account available financial, technical and human resources.

\section{Selection criteria}

The Centre Mersenne's governance sets its policy: publications should be peer-reviewed research publications; the articles are selected on behalf of a competent, scientifically independent editorial board; the publication's title is owned by a non-profit organisation (which can be an editorial board, a society...); journals web sites comply with OASPA ${ }^{18}$ 's "Principles of transparency and best practice in scholarly publishing ${ }^{19}$ ", the European Mathematical Society ${ }^{20}$ Code of Practice ${ }^{21}$ (if applicable)...

These are mostly aligned with Fair Open Access Alliance's principles ${ }^{22}$, while maybe less prescriptive on some issues, as the Centre Mersenne also intends to leave room for innovation. 


\section{Business model}

21

The Diamond Open Access model is one of the many names of Gold OA without APC. This means that publication costs should not be covered by authors nor by readers. But, they still have to be covered in some way.

In the Centre Mersenne's case, the structure of costs is as follows:

1. Infrastructure and maintenance, coordination;

2. Initial set-up costs per publication;

3. Training of editorial teams and staff;

4. Running costs for each publication, depending on the level of service, editorial organisation, and volume published.

The institutions supporting Mathdoc (CNRS, UGA) provide the Centre Mersenne all the staff necessary for the development and running of the infrastructure (1). They shall also support (2) and (3), with the existing resources, for about 4 journals a year.

In order for the service to be scalable and sustainable, running costs (4) will have to be borne by the journal. Its team will be responsible for finding funding for its running costs in order to operate smoothly. The typical scenario would be the case of a journal, sustained by an institution that engages its name and resources. That institution will get some visibility in return. Another scenario would be a publication selected by a consortium of libraries willing to encourage transition to Diamond Open Access or any other mechanism as long as they are scientifically sound and economically viable.

The Centre Mersenne is eager to evaluate and discuss any proposed model.

\section{Beginning of the Centre Mersenne}

The Centre Mersenne has been inaugurated in January 2018 with the publication of the first issue of the new journal Algebraic Combinatorics ${ }^{23}$. Algebraic Combinatorics was founded by the former editorial board of the Springer-published Journal of Algebraic Combinatorics who resigned in July 2017 and flipped their journal to fair OA. As the editors didn't have any formal (legal) publisher, the MathOA foundation ${ }^{24}$, which also helped with the flipping, took this role.

Three journals are currently applying to join the Centre Mersenne:

- a newly-created generalist mathematics journal, supported by French public institutions, willing to enlarge the number of alternative venues for Diamond OA;

- An existing journal published by a learned society, already OA but willing to get a more professional support;

- A new journal meant as an OA companion to an existing journal, thus anticipating a move to OA for a community quite removed from mathematics. This would be the first publication outside of mathematics discipline for the Centre Mersenne.

28 All the Cedram publications will be gradually migrated to the Centre Mersenne as its mathematical facet. This migration is expected to be completed before the end of this year. 
The Algebraic Combinatorics journal homepage

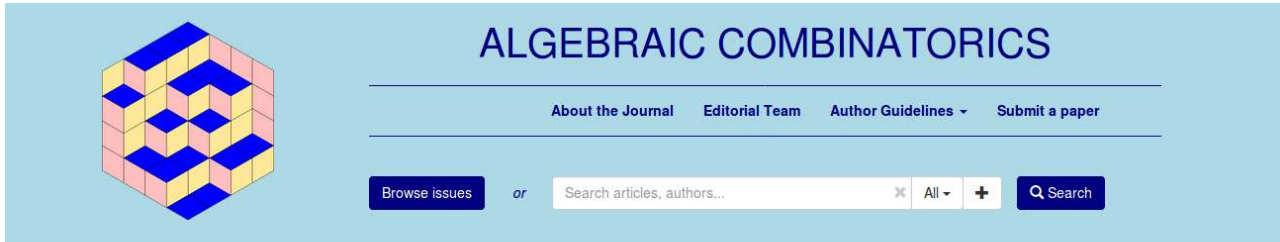

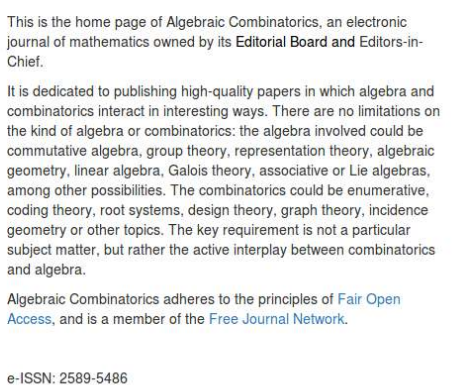

-ISSN: $2589-5486$
New articles

Permutrees
Pilaud, Vincent: Pons, Vivian

A Demazure crystal construction for Schubert

Assaf, Sami ; Schilling, Ann

Symmetry in Turán sums of squares

Raymond, Annie : Singh, Mohit: Thomas, Rekha

A property of the Birkhoff polytope

r. Barbara ; Ladisch, Frieder

View More

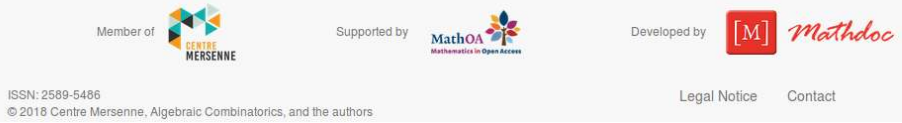

CNRS

The Centre Mersenne Member Journals

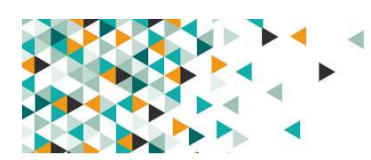

About Member journals

Accueil Member journats

The Centre Mersenne member Publications

Journals

- Algebraic Combinatorics

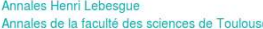

- Annales de linsititut Fourier

- Journal de lEcole polytechnique - Mathématiques

- Joumal de thérerie des nombres de Bordeaux

Maths Ir Actor

- Publications Mathématques de Besançon - Agébre et Théorie des Nomb

Books

- Michèle Audin : Le Séminarire de mathématiques 1933-1939

Proceedings

- Actes des rencor

- Joumées Équations aux dérivèes partielles

- Séminaire Equatilions aux dérivées partilles (Polytechniq

- Séminaire Laurent Schwartz - EDP è applications

CNRS 


\section{Conclusion}

The Centre Mersenne for open scientific publishing has gone public since January 2018. It is designed to be an open access scientific publishing infrastructure for the scientific communities publishing in LaTeX. The new platform has already been used to launch a new journal, and should disseminate about 15 journals, some of them new, some of them well established before the end of the year. We currently anticipate a growth of about 4 journals per year, with a balance between newly-created and pre-existing journals, as well as from across all scientific fields.

We hope this new venture will be one of the small incremental steps that shall eventually change the landscape of scientific publishing and enable the scientific communities to regain control over it.

\section{BIBLIOGRAPHY}

\section{References}

[1] Bouche, T., Miot, E., Vaudaine. C. (2018). "Le centre Mersenne pour l'édition scientifique ouverte.” In Gazette des mathématiciens, 155: 76-78. Available at: http://www.mathdoc.fr/publis/ smf_gazette_155_76-78.pdf

[2] Bouche, T., Laurent, Y., Sabbah, C. (2006). "L'édition sans drame." In Gazette des mathématiciens, 108: 86-88.

Available at: http://www.mathdoc.fr/publis/smf_gazette_108_86-88.pdf

[3] Cherhal-Cleverly, E. Heïgéas, L. (2005). "MathDoc and the Electronic Publishing of Mathematics." In Proceedings ElPub conference. Leuven, Belgique. Available at: http:// www.cedram.org/IMG/pdf/elpub.pdf

[4] Bouche, T., Labbe, O. “The New Numdam Platform." In: Geuvers h., England M., Hasan O., Rabe F., Teschke O. (Eds.) Intelligent Computer Mathematics. CICM 2017. LNCS, vol 10383: 70-82. Springer. Available at: https://zenodo.org/record/581405

[5] Bouche, T. (2006). “A PdfLaTeX-based automated journal production system.” In TUGboat, 27

(1): 45-50. Available at: http://www.mathdoc.fr/publis/tb86bouche.pdf

[6] Research Consulting (2017). “Towards a Competitive and Sustainable OA Market in Europe: A Study of the Open Access Market and Policy Environment." OpenAIRE. Available at: https:// blogs.openaire.eu/wp-content/uploads/2017/03/OA-market-report-28Final-13March-201729-1.pdf

[7] Solomon, DJ, Laakso, M., Björk, B.-C. (authors), Suber, P. (editor) (2016). "Converting Scholarly Journals to Open Access: A Review of Approaches and Experiences.” The Harvard Library. Available 
at: https://dash.harvard.edu/bitstream/handle/1/27803834/DASH\%20Version-Journal-flippingfinal-Aug4-2016-print-2.pdf?sequence=3

\section{NOTES}

1. LaTeX is a high-quality typesetting system; it includes features designed for the production of technical and scientific documentation. It is very popular in the scientific community because it enables to effectively typeset mathematics formulas.

2. CNRS for Centre National de la Recherche Scientifique - the French National Center for Scientific Research. CNRS' website address: http://www.cnrs.fr/

3. The newly-created university press of UGA, resulting from a merger of the publishing services in Grenoble in Human and Social Science and Science/Technical/Medical. UGA Editions' website address: https://www.uga-editions.com.

4. Article processing Charges: fees required by a publisher from the author to publish his/ her article in a journal.

5. Cedram's website address: http://www.cedram.org/

6. Cellule Mathdoc or Cellule de coordination documentaire nationale pour les mathematiques, develops services towards French librarians and research mathematicians such as Numdam or Cedram. Mathdoc's website address: http:// www.mathdoc.fr/

7. Numdam's website address: http://www.numdam.org/

8. DOI (Digital Object Identifier): a unique and long-lasting identifier for an electronic document or a dataset assigned by Crossref, of which the Centre Mersenne is a member. 9. Open Journal System, an open source journal management and publishing software, developed by the Public Knowledge Project. OJS website address: https://pkp.sfu.ca/ojs/.

10. OpenEdition's website address: https://www.openedition.org/?lang=en

11. Episciences' website address: https://episciences.org/

12. Scipost's website address: https://scipost.org/

13. ELibM's website address: https://www.elibm.org/

14. Zentralblatt Math (zbMATH) is an international abstracting and reviewing service in pure and applied mathematics. It contains about 4 million bibliographic entries.

ZbMATH's website address: https://zbmath.org/

15. Crossref is an official Digital Object Identifier (DOI) Registration Agency of the International DOI Foundation. Crossref's website address: https://www.crossref.org/ 16. The Open Archive Protocol for Metadata Harvesting (OAI-PMH) is a mechanism developed for harvesting metadata descriptions of records in an archive to make all publications available to a broader academic public.

17. CLOCKSS (the Controlled-Lots of Copy Keep Stuff Safe) is a non-profit "dark archive" founded by research libraries and academic publishers to ensure long-term preservation of online scholarly content. CLOCKSS' website address: https://www.clockss.org/clockss/ Home

18. OASPA is a OSAPA (Open Access Scholarly Publishers Association) an association aiming to support and represent the interests of Open Access (OA) journal and book publishers globally in all scientific, technical, and scholarly disciplines. OASPA's website address: https://oaspa.org/.

19. OASPA's criteria are available at: https://oaspa.org/membership/membershipcriteria/ 
20. The European Mathematical Society (EMS) is a learned society representing mathematicians throughout Europe. It promotes the development of all aspects of mathematics in Europe, in particular mathematical research. EMS' website address: http://euro-math-soc.eu/.

21. EMS code of practice is available at: http://euro-math-soc.eu/system/files/uploads/ COP-approved.pdf

22. Fair Open Access Alliance (FOAA) is composed of a group of scholars and librarians aimed at coordinating efforts towards sustainable open access scholarly publishing, following the principles of Fair Open Access. Fair Open Access' website address: https:// www.fairopenaccess.org/. FOAA principles are available at: https:// www.fairopenaccess.org/

23. Algebraic Combinatorics' website address: https://alco.centre-mersenne.org/

24. MathOA is a foundation aimed at facilitating and accelerating the switch to open access publishing in mathematics (broadly interpreted), using the principles of what we call Fair Open Access. MathOA’s website address: http://www.mathoa.org/

\section{ABSTRACTS}

The aim of this paper is to present the Centre Mersenne for Open Scientific Publishing, a new open access scientific publishing infrastructure for publications written in LaTeX.

The Centre Mersenne was launched in January 2018 with the first volume of the newly-created journal Algebraic Combinatorics.

This non-profit initiative hosted by French public institutions was created to address a growing need within the scientific community for alternative solutions simultaneously scalable, sustainable, trustworthy, of high quality and at fair price.

The Centre Mersenne supports publications such as journals, books and proceedings from any scientific discipline, provided they are written in LaTeX and engaged towards Diamond open access.

\section{INDEX}

Keywords: Electronic publishing, Publishing platform, Scientific publishing infrastructure, Open Access, Open access scientific publishing, LaTeX, Open access publishing, Scientific publishing, Scientific publication, Open sciences

\section{AUTHORS}

\section{THIERRY BOUCHE}

Université Grenoble Alpes, France

thierry.bouche@univ-grenoble-alpes.fr 


\section{EVELYNE MIOT}

Centre national de la recherche scientifique (CNRS-French National Center for Scientific Research), France

evelyne.miot@univ-grenoble-alpes.fr

\section{CÉLIA VAUDAINE}

Université Grenoble Alpes, France

celia.vaudaine@univ-grenoble-alpes.fr

(corresponding author) 